\title{
Using Trend Extrapolation Model to Predict the Needs of Elderly Care Talents in Beijing Institutions
}

\author{
Aijia Song ${ }^{1, a}$, Zhaoqi Peng ${ }^{2, b}$ \\ ${ }^{1}$ School of Economics and Management Beijing Jiaotong University Beijing, China \\ ${ }^{2}$ School of Economics and Management Beijing Jiaotong University Beijing, China
}

\begin{abstract}
China's population aging, and it is also a critical period for the country to actively respond to population aging. Under the background of the combination of medical care and nursing, institutional elderly care services, as an important branch of the multi-level elderly care service system, have become the main battlefield of the integrated medical and elderly care policy. Therefore, institutional care talents for the aged have also become a key link in improving the quality of life of the elderly population. This paper using trend extrapolation model to predict the needs of elderly care talents in institutions in Beijing, including nursing staff who provide basic living care and professional medical staff who provide services such as rehabilitation, medical treatment, nutrition, and psychological consultation. The results show that, in 2050, the demand for institutional elderly nursing staff in Beijing will exceed 150,000, and the demand for institutional elderly medical staff will reach about 20,000 .
\end{abstract}

\section{RESEARCH BACKGROUND}

\subsection{The aging situation in Beijing is severe, and the function of family care for the elderly continues to weaken}

The common international view is that when a country or region's elderly population over 60 accounts for $10 \%$ of the total population, the country or region is regarded as entering an aging society. According to data released by the Beijing Municipal Bureau of Statistics: as of the end of 2019, the permanent population of Beijing was 21.536 million, of which 3.713 million were people aged 60 and over, accounting for $17.2 \%$. It can be seen that the current aging situation in Beijing is already very severe. According to the "China Development Report 2020: Development Trends and Policies of China's Population Aging", by around 2022, China's population over the age of 65 will account for $14 \%$ of the total population, realizing the transition to an aging society; by 2050 , China Aging will reach its peak, and China's population over 65 will account for $27.9 \%$ of the total population. At the same time, family planning has created a "four-two-one" family structure for the 80th and 90th generations in cities and towns. Coupled with the pressure of survival competition and regional mobility, many young people are facing a huge burden of old-age care, gradually weaken the function of family support. At the same time, the traditional support consciousness has gradually faded. More and more elderly people are willing to choose socialized pension models such as institutional pension to reduce the burden on their children. This means that between 2020 and 2050, the demand for institutionalized elderly care and other socialized elderly care methods will increase significantly, and with that comes the demand for institutional elderly care talents.

\subsection{Beijing actively builds a pattern combining medical care and nursing for the aged}

The combination of medical care and nursing is a new type of elderly care model, which is the coordinated participation of traditional elderly service responsibility subjects and medical institutions. This is an old-age care model aimed at the elderly's chronic diseases, senile diseases and rehabilitation needs. It can not only provide life care and spiritual comfort in traditional elderly care services, but also provide professional and convenient medical diagnosis and treatment, nursing care, critical illness rehabilitation, hospice care and other services for disabled and semi-disabled elderly people suffering from diseases [1].

In November 2019, the Central Committee of the Communist Party of China and the State Council issued the "National Plan for Actively Responding to Population Aging in the Medium and Long Term", which pointed out the need to establish and improve a comprehensive and continuous elderly health service system, including health education, preventive health care, disease diagnosis and treatment, rehabilitation care, etc. At the same time, a multi-level elderly care service system based on the home, supported by the community, fully developed institutions,

"Corresponding author: ${ }^{\mathrm{a}} 3156927465 @$ qq.com, ${ }^{\mathrm{b}}$ zhqpeng@bjtu.edu.cn 
and organically integrated medical care and nursing care should be improved. Under the guidance of national policies, Beijing's existing medical-care integration models are mainly divided into three types: (1)Elderly care and care institutions are equipped with medical conditions through supporting settings, independent settings or agreement cooperation. As of the end of 2018, $95 \%$ of the 526 elderly care institutions in Beijing were able to provide medical and health services in different forms. (2)Establishing professional elderly medical institutions or setting up elderly wards in large medical institutions. Beijing has 8 medical institutions above the second level for the elderly, and 12 medical institutions with geriatric departments. (3)The old-age care center that combines medical care and care established by the government in the streets and communities [2]. Among the three types of old-age care, only the institutional oldage care model needs to be equipped with professional medical personnel. The other two methods cooperate with medical institutions to achieve the purpose of combining medical care and nursing. Therefore, the policy of integrating medical care and elderly care actually puts forward higher requirements on the institutional elderly care personnel.

\section{THE CURRENT SITUATION AND PROBLEMS}

\subsection{Both the number and the professionalism of the elderly nursing staff is insufficient to meet the high-level needs of the elderly}

According to statistics, in 2019, there were more than 6,500 elderly nursing staffs in Beijing. However, the demand for nursing staff is 24,000 to 30,000 . At the same time, there are problems such as recruitment difficulties, lack of talents, and serious loss of existing employees, which cause the supply of elderly care services to be far from meeting the development needs. It is mainly reflected in the following three aspects [2]: First, the overall number cannot meet the reasonable ratio of the elderly population to the caregiver. Second, the service content cannot meet the high-level needs of the elderly. They are limited to basic living care and lack professional medical care services such as rehabilitation, medical care, nutrition, and psychological consultation. Third, the quality and professionalism of elderly nursing staff are limited. The professional qualification system for elderly nursing staff in China started relatively late, and there is no supervision on the entry threshold of this industry. As a result, only a small part of the existing elderly care workers have undergone professional skills training and obtained vocational qualification certificates, and most of them show the characteristics of low educational level, low professionalism, and high average age.

\subsection{The policy of integration of medical care and nursing puts forward new requirements}

In October 2019, 12 departments including the National Health Commission, the Ministry of Civil Affairs, and the National Development and Reform Commission jointly issued the "Several Opinions on Further Promoting the Development of Integrated Medical Care." It pointed out that it is necessary to strengthen the connection between medical and health and elderly care services, promote team building, improve the training of professional talents in geriatrics, rehabilitation, and nursing, and support medical personnel to practice in medical care institutions. Under such a policy background, the staffing of elderly care institutions requires not only traditional nursing personnel who meet the basic physiological needs of the elderly, but also professional medical personnel to provide health assessment, first aid, and medical rehabilitation services for the elderly [3]. However, the staffing of existing elderly care institutions in Beijing is less that meet this standard, and the prices of other institutions that meet the standards are much higher.

\section{Prediction OF DEMAND FOR INSTITUTIONAL ELDERLY CARE TALENTS IN BEIJING}

From the previous analysis, we can see that 2020-2050 is a period of rapid development of China's population aging, and it is also a critical period for the country to actively respond to population aging. As an important branch of the multi-level elderly care service system, institutional elderly care services are also the main battlefield of the medical-care integration policy. The supply of elderly care services it provides in the future cannot be underestimated. Therefore, this section intends to forecast the demand for institutional elderly care talents in Beijing from 2020 to 2050 , including nursing staff who provide basic living care and professional medical staff who provide services such as rehabilitation, medical treatment, nutrition, and psychological consultation. In turn, it provides a theoretical reference for building a high-quality institutional elderly care service and a product supply system that combines medical and nursing.

This paper adopts the medium plan data provided by MA Xiao-hong and others when predicting the trend of changes in the registered population in the next 50 years in Beijing [4], from which I obtained the number of registered population in Beijing from 2020 to 2050 and the proportion of the elderly over 60 years old. Using the above data to calculate the number of elderly people with household registration in Beijing from 2020 to 2050, as shown in Table I. According to the "9064" elderly care service development goal proposed by the Beijing Municipal Civil Affairs Bureau and the Planning Commission in 2015 , by $2020,90 \%$ of the elderly rely on family care, $6 \%$ of the elderly receive elderly care services in the community, and $4 \%$ of the elderly will live in institutions for elderly care. Assuming that the elderly care service methods in the next 50 years are in line with the proportions in the plan, combined with the prediction results of the number of elderly population, we can then 
calculate the number of beds required for institutional elderly care services in Beijing from 2020 to 2050, as shown in Table I.

TABLE I. THE NUMBER OF BEDS REQUIRED FOR THE ELDERLY IN BEIJING INSTITUTIONS FROM 2020 TO 2050

\begin{tabular}{|c|c|c|c|}
\hline Years & $\begin{array}{c}\text { Number of } \\
\text { registered } \\
\text { population in } \\
\text { Beijing /ten } \\
\text { thousand (*) }\end{array}$ & $\begin{array}{c}\text { Number of } \\
\text { registered } \\
\text { population } \\
\text { over 60 years } \\
\text { old /ten } \\
\text { thousand }\end{array}$ & $\begin{array}{c}\text { Number of beds } \\
\text { required by } \\
\text { institutions for the } \\
\text { elderly /ten } \\
\text { thousand }\end{array}$ \\
\hline 2020 & $\begin{array}{c}1327 \\
(0.2698)\end{array}$ & 358.0246 & 14.320984 \\
\hline 2025 & $\begin{array}{c}1354 \\
(0.3147)\end{array}$ & 426.1038 & 17.044152 \\
\hline 2030 & $\begin{array}{c}1366 \\
(0.3395)\end{array}$ & 463.757 & 18.55028 \\
\hline 2035 & $\begin{array}{c}1370 \\
(0.3515)\end{array}$ & 481.555 & 19.2622 \\
\hline 2040 & $1366(0.358)$ & 489.028 & 19.56112 \\
\hline 2045 & 1354 & 519.5298 & 20.781192 \\
\hline 2050 & $\begin{array}{c}13337) \\
(0.4045)\end{array}$ & 539.1985 & 21.56794 \\
\hline
\end{tabular}

In recent years, the Beijing Municipal Civil Affairs Bureau has carried out the star-rating work of the service quality of elderly care service institutions in accordance with national standards and related documents. The document provides detailed regulations on the scale and staffing of various star-rated care institutions (see Table II).

TABLE II. ThE GRADE EVALUATION AND ClASSIFICATION STANDARDS OF BEIJING ELDERLY CARE INSTITUTIONS

\begin{tabular}{|c|c|c|c|c|}
\hline $\begin{array}{c}\text { Elderly } \\
\text { care } \\
\text { institutio } \\
\text { n star }\end{array}$ & $\begin{array}{c}\text { Scale } \\
\text { (number of } \\
\text { beds) }\end{array}$ & $\begin{array}{c}\text { The ratio of } \\
\text { nursing } \\
\text { staff to } \\
\text { elderly }\end{array}$ & $\begin{array}{c}\text { Medical } \\
\text { staffing } \\
\text { requiremen } \\
\text { ts }\end{array}$ & $\begin{array}{c}\text { Work- } \\
\text { rest } \\
\text { ratio* }\end{array}$ \\
\hline One- star & above 50 & $1: 6 \sim 7$ & $\begin{array}{c}\text { Equipped on } \\
\text { demand }\end{array}$ & $1 / 4$ \\
\hline Two-star & above 100 & $1: 6 \sim 7$ & 2 人 & $1 / 4$ \\
\hline $\begin{array}{c}\text { Three- } \\
\text { star }\end{array}$ & above 150 & $1: 4 \sim 6$ & $3 \sim 4$ 人 & $1 / 3 \sim 4$ \\
\hline Four-star & above 200 & $1: 4$ & $10 \sim 13$ 人 & $1 / 2 \sim 3$ \\
\hline Five-star & above 200 & $1: 3 \sim 4$ & $10 \sim 13$ 人 & $1 / 2 \sim 3$ \\
\hline
\end{tabular}

According to the above standards, the overall staffing requirements of various star-rated elderly care institutions can be calculated. For example, I suppose that all five-star elderly care institutions accept exactly 200 elderly people (which is the minimum standard for the scale of five-star elderly care institutions), and the ratio of nursing staff to elderly persons, medical staffing and work-rest ratio standards are all set to the lowest value. Then we inferred: number of elderly people corresponding to each nursing staff in a five-star elderly care institution = $200 /(200 \div 4 \times(1+2)) \approx 1.3$, and number of elderly people corresponding to each medical staff in five-star elderly care institutions $=200 /(10 \times(1+2) \quad) \approx 7$. In the same way, the overall staffing standards of various star-rated elderly care institutions can be calculated as shown in Table 3 .
TABLE III. STAFFING STANDARDS OF VARIOUS STAR-RATED ELDERLY CARE INSTITUTIONS

\begin{tabular}{|c|c|c|c|}
\hline $\begin{array}{c}\text { Elderly } \\
\text { care } \\
\text { institution } \\
\text { star }\end{array}$ & $\begin{array}{c}\text { Nursing staff: } \\
\text { Elderly }\end{array}$ & $\begin{array}{c}\text { Medical staff: } \\
\text { Elderly }\end{array}$ & $\begin{array}{c}\text { Proportion of } \\
\text { different star- } \\
\text { rated elderly care } \\
\text { institutions in } \\
\mathbf{2 0 1 9}\end{array}$ \\
\hline One-star & $1: 1.4$ & $\begin{array}{c}\text { Equipped on } \\
\text { demand }\end{array}$ & $9.24 \%$ \\
\hline Two-star & $1: 1.4$ & $1: 10$ & $69.79 \%$ \\
\hline Three-star & $1: 1.5$ & $1: 12.5$ & $5.72 \%$ \\
\hline Four-star & $1: 1.3$ & $1: 7$ & $10.56 \%$ \\
\hline Five-star & $1: 1.3$ & $1: 7$ & $4.69 \%$ \\
\hline
\end{tabular}

Assuming that the distribution of star-rated elderly care institutions in Beijing from 2020 to 2050 is consistent with that in 2019 , combining the data in Table 3 can calculate the demand for institutional elderly care staff in Beijing from 2020 to 2050. The calculation formula is:

$$
\mathrm{Dn}_{\mathrm{i}}=\mathrm{B}_{\mathrm{i}} \times \sum_{\mathrm{i}=1}^{5} P_{j} \times R n_{j}
$$

Among them, Dn represents the demand for institutional elderly nursing staff in Beijing in a certain year; $\mathrm{B}$ represents the number of beds required for the institutional elderly care in Beijing in a certain year; $P$ represents the proportion of a star-rated elderly care institutions; and Rn represents the ratio of nursing staff to elderly in a star-rated elderly care institution. In addition, $i$ represents the year $(i=2020,2025,2030,2035,2040$, $2045,2050)$; j represents the star rating of the elderly care institution $(\mathrm{j}=1,2,3,4,5)$. The calculation results are shown in Table 4.

In the same way, the formula for calculating the demand for institutional elderly medical staff in Beijing from 2020 to 2050 is as follows:

$$
\mathrm{Dm}_{\mathrm{i}}=\mathrm{B}_{\mathrm{i}} \times \sum_{\mathrm{i}=1}^{5} P_{j} \times R m_{j}
$$

Among them, Dm represents the demand for institutional elderly medical staff in Beijing in a certain year; Rm represents the ratio of medical staff to elderly in a star-rated elderly care institution; the rest has the same meaning as above. The calculation results are shown in Table 4.

TABLE IV. FORECAST OF DEMAND FOR INSTITUTIONAL ELDERLY CARE TALENTS IN BEIJING FROM 2020 TO 2050

\begin{tabular}{|c|c|c|c|}
\hline Years & $\begin{array}{c}\text { Demand for } \\
\text { nursing staff } \\
\text { /ten thousand }\end{array}$ & $\begin{array}{c}\text { Demand for } \\
\text { medical staff } \\
\text { /ten thousand }\end{array}$ & $\begin{array}{c}\text { Demand for } \\
\text { elderly care } \\
\text { talents } \\
\text { /ten thousand }\end{array}$ \\
\hline 2020 & 10.31026854 & 1.377022307 & 11.68729085 \\
\hline 2025 & 12.27078978 & 1.638866262 & 13.90965604 \\
\hline 2030 & 13.35511361 & 1.783686747 & 15.13880035 \\
\hline 2035 & 13.86765425 & 1.852140823 & 15.71979507 \\
\hline 2040 & 14.08285912 & 1.880883227 & 15.96374235 \\
\hline
\end{tabular}




\begin{tabular}{|c|c|c|c|}
\hline Years & $\begin{array}{c}\text { Demand for } \\
\text { nursing staff } \\
\text { /ten thousand }\end{array}$ & $\begin{array}{c}\text { Demand for } \\
\text { medical staff } \\
\text { /ten thousand }\end{array}$ & $\begin{array}{c}\text { Demand for } \\
\text { elderly care } \\
\text { talents } \\
\text { /ten thousand }\end{array}$ \\
\hline 2045 & 14.9612394 & 1.998198235 & 16.95943764 \\
\hline 2050 & 15.52765182 & 2.073847335 & 17.60149915 \\
\hline
\end{tabular}

\section{Suggestions ON TALENT CULTIVATION OF ELDERLY CARE INSTITUTIONS}

\subsection{Establish a multi-channel talent development mechanism}

Judging from the forecast results, in 2050, the demand for institutional elderly nursing staff in Beijing will exceed 150,000 , and the demand for institutional elderly medical staff will reach about 20,000. Considering that there are less than 10,000 elderly care workers in Beijing, at least 20,000 elderly care workers should be trained every year to basically meet the needs by 2050 .

Therefore, it is necessary to establish a multi-channel talent development mechanism to expand the team of elderly care workers. On the one hand, increasing the enrollment rate of related majors by setting up student subsidies, scholarships and other policies. On the other hand, we could provide authoritative professional nursing training courses in the field of adult education, and conduct them through various channels such as online and offline. As for rural laborers and urban laborers with difficulty in finding jobs, employment subsidies and free online and offline training can be used to expand the nursing talent team [2].

\subsection{Improve the salaries and benefits of elderly care staff, and reasonably plan career promotion paths}

We must retain talent. Although several colleges and universities in Beijing have opened senior service and management majors, the willingness of nursing talents and nurses who graduated from professional colleges to enter the elderly care industry is low, resulting in a large loss of professional talents. This is because the work of elderly care workers is generally characterized by low wages, high labor intensity, poor working environment, communication difficulties and low social status. At the same time, this also makes the turnover rate of on-the-job care workers higher [5]. Therefore, the government should guarantee the salaries of elderly care workers at the policy and legal levels. As well as attract and retain talents through high wages and high benefits such as settlement policies. It is necessary to improve the appraisal system for practitioners, and rationally plan the career promotion and development path of elderly care personnel. The government should also guide the correct direction of public opinion, weaken people's prejudice against the profession of elderly caregivers, improve the social status of them, and thereby enhance the professional identity of elderly caregivers.

\subsection{Establish a complete and professional personnel training system}

First of all, strengthening the construction of related disciplines in the nursing profession. The government and the Education Bureau can stipulate that the nursing colleges and universities must cover medical, rehabilitation, physiotherapy, psychological counseling, nutrition and other disciplines in the nursing care professional courses. Second, strictly checking industry access standards, and setting up different job responsibilities and corresponding qualification examinations for different elderly service positions. For on-the-job elderly care workers, strengthen their relevant knowledge and skills training. In addition to basic life care skills, the training content should also include medical knowledge, nursing knowledge, rehabilitation physiotherapy, psychological counseling, and nutrition. In order to check and consolidate the training results in time, a unified skill assessment and appraisal should also be arranged regularly. These methods could be used to ensure the professionalism of nursing staff and improve the overall quality of them [2].

\subsection{Establish a rotation system for doctors and nurses, and cultivate compound talents with both medical and nursing care}

China's integrated medical and elderly care model is in its infancy, so there is still a big gap in the training and supply of integrated medical and elderly care service personnel. In the short term, relevant policies can be introduced to enrich the types of senior care talents. On the basis of the existing elderly care workers, institutional heads, social workers and volunteers, taking into account the responsibilities of existing positions and the diverse needs of the elderly, we can add professional medical staff, psychological consultants, and physical therapist, etc. At the same time, it is necessary to ensure that medical staff in elderly care institutions enjoy the same wages and benefits, title evaluation, and promotion path as other medical and health institutions. This can be achieved by implementing a rotation system for doctors and nurses in nearby hospitals, allowing everyone to take turns involuntarily to provide professional medical services to elderly care institutions, and their remuneration is the same as that of the hospital. In the long run, the training system for cultivate compound talents with both medical and nursing care can be improved, so that they can provide some basic medical services such as basic medicine, rehabilitation physiotherapy and psychological counseling. For those elderly people who are seriously ill, they could still taken care of by medical institutions set up in the elderly care institutions or medical institutions cooperating with the elderly care institutions, so that they can receive more professional medical services.

\section{REFERENCES}

1.YANG Ju-hua, DU Sheng-hong. The combination of medical care and nursing under the background of 
population aging: ideas, challenges and countermeasures $[\mathrm{J}]$. Journal of Wuhan University of Science and Technology (Social Science Edition), 2018, 20(4): 401-409.

2.GUO Li-jun, BAO Yong, HUANG Chun-yu, ZHANG Jin, WANG Hai-yan. China's senior care personnel training system $[\mathrm{J}]$. Chinese Journal of Gerontology, 2019, 39(14): 3576-3581.

3.YANG Xue-min, XU Lan, GUI Yan-hua, XU Ru. Discussion on Nursing Service under the Current
Situation of Nursing Care Model in China. [J]. China Health Industry, 2016, 13(8): 18-20.

4.MA Xiao-hong, HOU Ya-fei. A Study on Beijing's Population Variation Trend in the Future 50 Years[J]. Market \& Demographic Analysis, 2004, 10(2):4649,62.

5.LIU Yao, HUANG Yue, JU Mei. Research advances in nursing human resources in nursing institution for the aged with the combination of medical care and pension in China[J]. Journal of Southwest Medical University, 2019, 42(1): 81-84. 